\title{
Role of Iron (Fe) in Body
}

\author{
Dr. C. P. Gupta \\ Department of Chemistry St. Andrew' P.G. College Gorakhpur 273001
}

\begin{abstract}
Iron is an essential element for most life on Earth, including human beings by participating in a wide variety of metabolic processes, including oxygen transport, DNA synthesis, and electron transport. Iron is needed for a number of highly complex processes that continuously take place on a molecular level and that are indispensable to human life, e.g. the transportation of oxygen around your body. Iron is required for the production of red blood cells (a process known as haematopoiesis), but it's also part of haemoglobin (that is the pigment of the red blood cells) binding to the oxygen and thus facilitating its transport from the lungs via the arteries to all cells throughout the body. About 70\% of the body's iron is bound to hemoglobin in red blood cells. The rest is bound to other proteins (transferrin in blood or ferritin in bone marrow) or stored in other body tissues. When red blood cells die, their iron is released and carried by transferrin to the bone marrow and to other organs such as the liver and spleen. In the bone marrow, iron is stored and used as needed to make new red blood cells. Once the oxygen is delivered the iron (as part of haemoglobin) binds the carbon dioxide which is then transported back to the lung from where it gets exhaled. Iron is also involved in the conversion of blood sugar to energy. Metabolic energy is crucial for athletes since it allows muscles to work at their optimum during exercise or when competing. The production of enzymes (which play a vital role in the production of new cells, amino acids, hormones and neurotransmitters) also depends on iron, this aspect becomes crucial during the recovery process from illnesses or following strenuous exercise or competing.
\end{abstract}

\section{Introduction}

Iron has several vital functions in the body. It serves as a carrier of oxygen to the tissues from the lungs by red blood cell haemoglobin, as a transport medium for electrons within cells, and as an integrated part of important enzyme systems in various tissues. The physiology of iron has been extensively reviewed. ${ }^{[1-6]}$ Most of the iron in the body is present in the erythrocytes as haemoglobin, a molecule composed of four units, each containing one heme group and one protein chain. The structure of haemoglobin allows it to be fully loaded with oxygen in the lungs and partially unloaded in the tissues (e.g., in the muscles). The iron-containing oxygen storage protein in the muscles, myoglobin, is similar in structure to haemoglobin but has only one heme unit and one globin chain. Several iron-containing enzymes, the cytochromes, also have one heme group and one globin protein chain. These enzymes act as electron carriers within the cell and their structures do not permit reversible loading and unloading of oxygen. Their role in the oxidative metabolism is to transfer energy within the cell and specifically in the mitochondria. Other key functions for the iron-containing enzymes (e.g., cytochrome P450) include the synthesis of steroid hormones and bile acids; detoxification of foreign substances in the liver; and signal controlling in some neurotransmitters, such as the dopamine and serotonin systems in the brain. Iron is reversibly stored within the liver as ferritin and hemosiderin whereas it is transported between different compartments in the body by the protein transferrin. The primary function of hemoglobin $(\mathrm{Hb})$ is to transport oxygen. Since oxygen is not very soluble in water (the major constituent of blood), an oxygen transport protein must be used to allow oxygen to be 'soluble'. Hemoglobin $(\mathrm{Hb})$ is the oxygen transport protein used in the blood of vertebrates. It is composed of 4 polypeptide chain, each of which contains one iron ion. The iron is the site of oxygen binding; each iron can bind one $\mathrm{O}_{2}$ molecule thus each hemoglobin molecule is capable of binding a total to four (4) $\mathrm{O}_{2}$ molecules. In humans, the average hemoglobin concentration is $16 \mathrm{~g} / 100 \mathrm{ml}$. This means that there are approximately $150,500,000,000,000,000,000$ hemoglobin molecules in $100 \mathrm{ml}$ of whole blood. How many possible binding sites for oxygen are contained in $100 \mathrm{ml}$ of blood? How many $\mathrm{O}_{2}$ molecules can be carried by $100 \mathrm{ml}$ of blood if the hemoglobin is completely saturated (meaning every possible binding site is filled) with oxygen? It is important that you remember that the purpose of $\mathrm{Hb}$ is to pickup oxygen at the lungs and to deliver it to the tissues.

However, iron concentrations in body tissues must be tightly regulated because excessive iron leads to tissue damage, as a result of formation of free radicals. Disorders of iron metabolism are among the most common diseases of humans and encompass a broad spectrum of diseases with diverse clinical manifestations, ranging from anemia to iron overload and, possibly, to neurodegenerative diseases. The molecular understanding of iron regulation in the body is critical in identifying the underlying causes for each disease and in providing proper diagnosis and treatments. Recent advances in genetics, molecular biology and biochemistry [7] of iron metabolism have assisted in elucidating the molecular mechanisms of iron homeostasis.. Functional studies of these gene products have expanded our knowledge at the molecular level about the pathways of iron 
metabolism and have provided valuable insight into the defects of iron metabolism disorders. In addition, a variety of animal models have implemented the identification of many genetic defects that lead to abnormal iron homeostasis and have provided.

\section{The Heme Porphyrin}

Although the hemoglobin and myoglobin molecules are very large, complex proteins, the active site is actually a non-protein group called heme. The heme consists of a flat organic ring surrounding an iron atom. The organic part is a porphyrin ring based on porphin (a tetrapyrrole ring), and is the basis of a number of other important biological molecules, such as chlorophyll and cytochrome. ${ }^{[8]}$ The ring contains a large number of conjugated double bonds, which allows the molecule to absorb light in the visible part of the spectrum. The iron atom and the attached protein chain modify the wavelength of the absorption and give hemoglobin its characteristic colour. Oxygenated hemoglobin (found in blood from arteries) is bright red, but without oxygen present (as in blood from veins), hemoglobin turns a darker red ${ }^{[9]}$ Venous blood is often depicted as blue in colour in medical diagrams, and veins sometimes look blue when seen through the skin. The appearance of blood as dark blue is a wavelength phenomenon of light, having to do with the reflection of blue light away from the outside of venous tissue if the vein is $\sim 0.02$ inches deep or more.<smiles>C1=C/C2=C\C=C\C3=C\c4ccc([nH]4)/C=c4/cc/c(n4N3)=C/C1=N2</smiles>

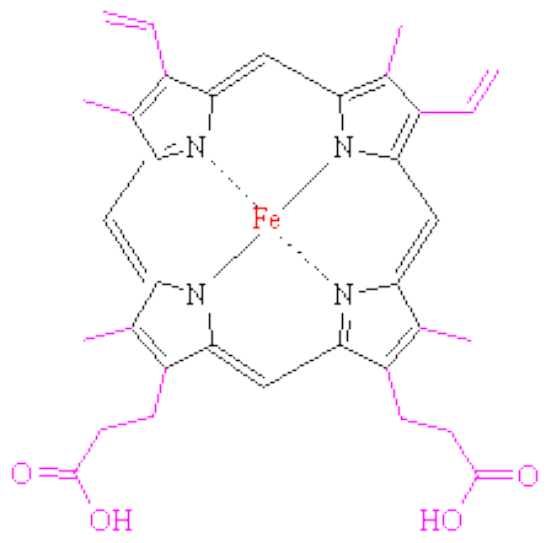

Fig.1. Porphin - the building block of heme

Fig. 2. Heme, the non-protein active site within myoglobin and hemoglobin. The side-groups which have been added to porphine are highlighted in magenta, and the central iron atom is shown in red.

\section{Reversible Binding of Oxygen}

The iron atom in heme binds to the 4 nitrogen atoms in the centre of the porphyrin ring, but this leaves two free bonding sites for the iron, one on either side of the heme plane. The heme group is located in a crevice in the myoglobin molecule, surrounded by non-polar residues except for two polar histidines. ${ }^{[10]}$ 


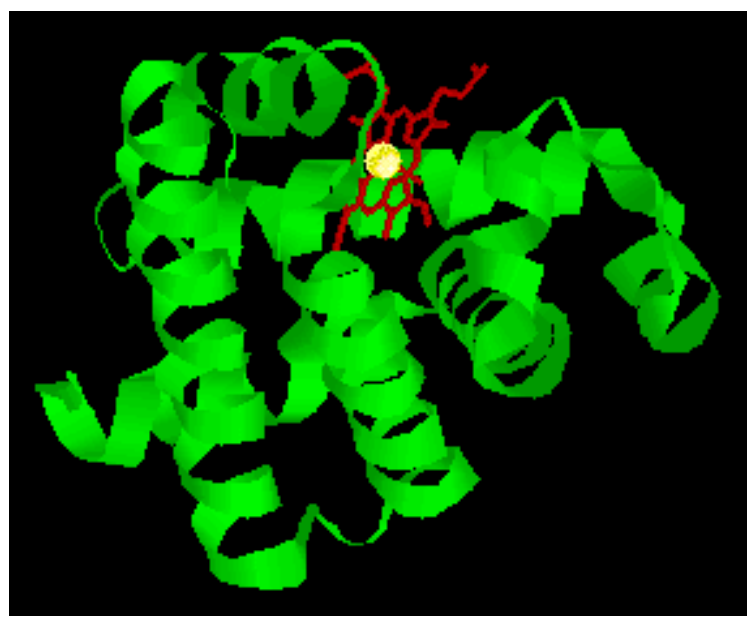

Fig. 3. Structure of the myoglobin protein with the position of the heme group highlighted
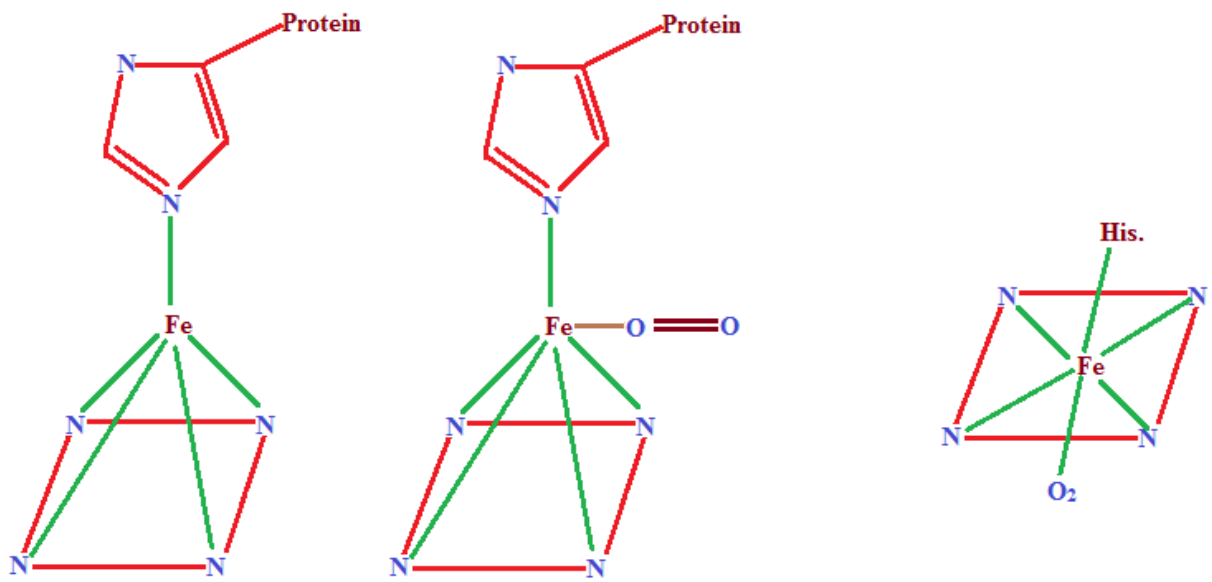

One of the free bonding sites of iron is joined to one of these histidines, leaving the final bonding site on the other side of the ring available to bond with oxygen. The second histidine group is nearby, and serves several purposes. It modifies the shape of the crevice so that only small molecules can get in to react with the iron atom, and it also helps to make the reaction reversible, such that the oxygen can be released when required by nearby tissues. It is amazing to realize that the whole complex 3-dimensional structure of the large myoglobin protein is designed purely to produce exactly the correct shaped crevice, with the correct two histidine groups in the right positions to facilitate this reversible oxygen uptake.

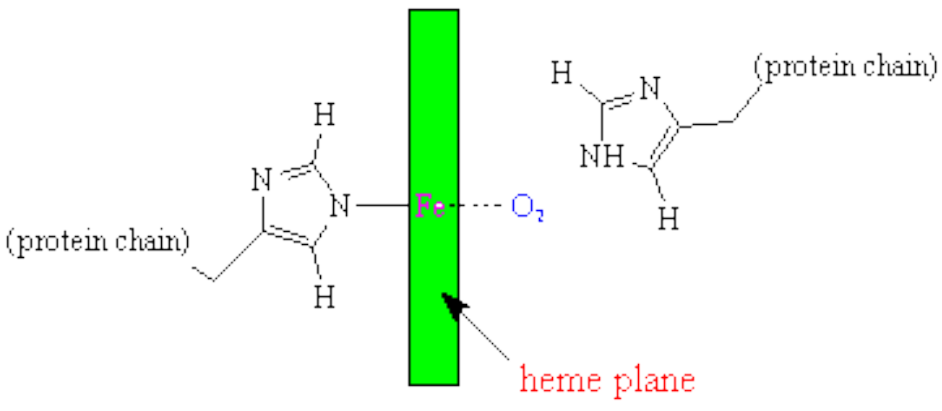

Fig. 4. Schematic diagram of the oxygen-binding site in myoglobin. 


\section{Hemoglobin}

Hemoglobin consists of 4 myoglobin units joined together, and its action with respect to uptake of oxygen is similar, but more complex. When we breathe, oxygen in the lungs passes through the thin-walled blood vessels and into the red blood cells, where it binds to the hemoglobin, turning it into the bright red oxyhemoglobin. The blood then passes around the body until it reaches cells and tissues which require oxygen to sustain their processes. These cells are rich in $\mathrm{CO}_{2}$, which is a waste product of these processes. The $\mathrm{CO}_{2}$ displaces the weakly-bound $\mathrm{O}_{2}$ and forms carbaminohemoglobin, which then travels in the bloodstream back around to the lungs where it is again displaced by oxygen.

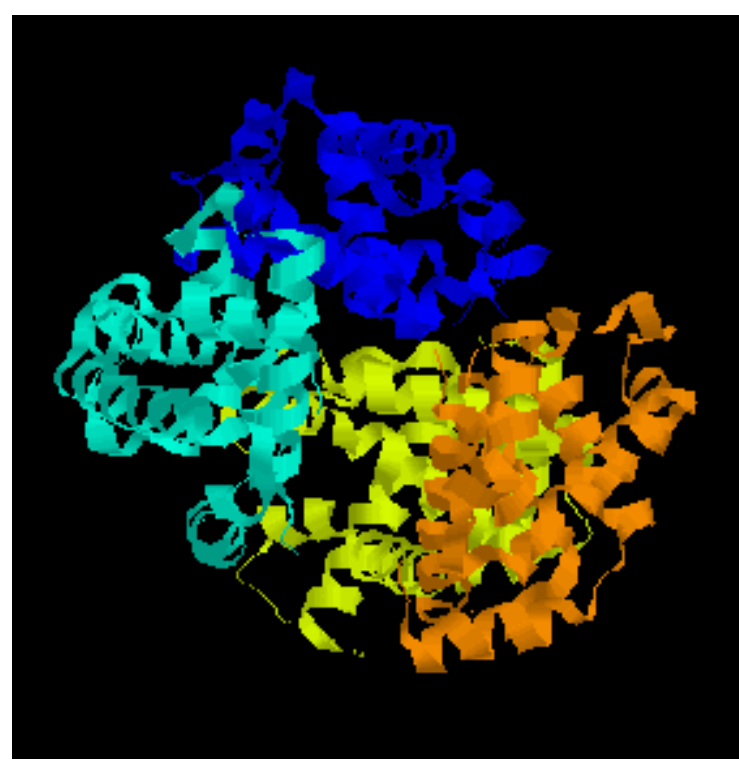

Fig.5 A ribbon diagram of the structure of hemoglobin. The 4 different myoglobin units are shown in different colours.

Both $\mathrm{O}_{2}$ and $\mathrm{CO}_{2}$ bind reversibly to hemoglobin, but certain other molecules, like carbon monoxide, are small enough to fit into the protein crevice, but form such strong bonds with the iron that the process is irreversible. Thus high concentrations of CO rapidly use up the body's limited supply of hemoglobin molecules, and prevent them from binding to oxygen. This is why CO is poisonous - the affected person rapidly dies of asphyxiation because his blood is no longer able to carry enough oxygen to keep the tissues and brain supplied. Hemoglobin binding affinity for CO is 200 times greater than its affinity for oxygen, meaning that small amounts of $\mathrm{CO}$ dramatically reduces hemoglobin's ability to transport oxygen. When hemoglobin combines with $\mathrm{CO}$, it forms a very bright red compound called carboxyhemoglobin. When inspired air contains $\mathrm{CO}$ levels as low as $0.02 \%$, headache and nausea occur. If the $\mathrm{CO}$ concentration is increased to $0.1 \%$, unconsciousness will follow. In heavy smokers, up to $20 \%$ of the oxygen active sites can be blocked by CO. Another poisonous molecule that binds to hemoglobin is hydrogen cyanide $(\mathrm{HCN})$. Once cyanide is taken into the blood stream the majority (92-99\%) is found bound to hemoglobin in red blood cells. From there it is taken to the body's tissues where it binds to an enzyme called cytochrome oxidase and stops cells from being able to use oxygen. The Fe porphyrin complex without the accompanying protein is oxidized irreversibly to Fe (III) by molecular $\mathrm{O}_{2}$ to give $\mu-\mathrm{O}_{2}$ bridged dimeric product $\left(\mathrm{Fe}-\mathrm{O}_{2}-\mathrm{Fe}\right)$. However this unproductive reaction is prevented by the protein environment. The result is that the $\mathrm{Fe}$ (II) complex can survive long enough to bind and release $\mathrm{O}_{2}$.

\section{Oxygen Binding to Hemoglobin}

The $\mathrm{O}-\mathrm{O}$ stretch that is observed by difference infrared techniques at around $1105 \mathrm{~cm}^{-1}$ for oxyhemoglobin and oxymyoglobin ${ }^{[1]}$ clearly categorizes the dioxygen moiety as a superoxo species, that is the order of the $\mathrm{O}-\mathrm{O}$ bond about 1.5. Considerable ink has been spilled about the nature of the $\mathrm{Fe}-\mathrm{O}_{2}$ fragment since Pauling's original suggestion ${ }^{[12]}$ in 1948 that dioxygen binds to iron in an end-on bent fashion:

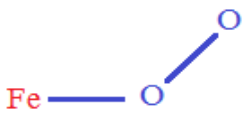

He subsequently reaffirmed this geometry, and proposed that hydrogen bonding between the coordinated dioxygen and the distal imidazole $\mathrm{H}-\mathrm{N}$ group was important in stabilizing the $\mathrm{Fe}-\mathrm{O}_{2}$ species. ${ }^{[13]}$ in an alternative model Weiss proposed that a low-spin $\mathrm{Fe}^{\mathrm{III}}$ centre $(\mathrm{S}=1 / 2)$ was very strongly 
antiferromagenatically coupled to a superoxide anion radical $(S=1 / 2) \cdot{ }^{[14]}$ a triangular peroxomode has also been advanced. ${ }^{[15,16]}$ The problem has been how to resolve the observed diamegnatism of oxyhemoglobin ${ }^{[17,18]}$ with UV-visible, $\mathrm{x}$-ray absorption and resonance Raman spectroscopic characterstics ${ }^{[19]}$ that are distinctly different from those of $\mathrm{Fe}^{\mathrm{II}}$ systems (such as carbonmonoxyhemoglobin or cyanomethemoglobin). Any adequate theoretical treatment must also explain how iron-porphyrin systems can bind not only $\mathrm{O}_{2}$ but also $\mathrm{CO}$, NO,alkyl isocyanides, and alkyl-nitroso moieties. A simple qualitative model presented by Wayland and coworkers ${ }^{[20,21]}$ conveniently summarizes ligand-binding geometries of cobalt and iron porphyrins. Although a reasonable quantative theoretical consensus exists for 1:1 cobalt-dioxygen species, the same cannot be said yet for iron dioxygen systems. Carbon monoxide (CO) generally binds more strongly to heamoglobin than does dioxygen, hence causing carbon-monoxide poisoning. In addition to being readily available from car exhausts and tobacco smoke to convert oxyhemoglobin to carbonmonoxyhemoglobin, $\mathrm{CO}$ is produced in the catabolism of heme molecules ${ }^{[22]}$ Thus under even the most favorable of condition, about 3 percent human hemoglobin is in the carbonmonoxy form. When $\mathrm{CO}$ binds to a single metal atom in nonbiological systems, without exception it does so through the carbon atom and in linear manner. ${ }^{[23]}$

$\mathrm{Fe}^{\mathrm{II}}+\mathrm{C} \equiv \mathrm{O}^{+} \rightarrow \quad \mathrm{Fe}-\mathrm{C} \equiv \mathrm{O}$

Model systems for carbonmonoxy (also called carbonyl) hemoglobin show a geometry similar to that of the $\mathrm{Fe}-\mathrm{C} \equiv \mathrm{O}$ group, linear or nearly so and essentially perpendicular to the porphyrin plane ${ }^{[24,-28]}$.The biochemical literature is littered with reports that this is not the geometry adopted by $\mathrm{CO}$ in binding to haemoglobins. ${ }^{[29,30]} \mathrm{We}$ will return to this topic later in this chapter, since the physiological consequences are potentially important.

The primary factor that determines how much oxygen is actually bound to hemoglobin is the partial pressure of oxygen $\left(\mathrm{pO}_{2}\right)$ in the hemoglobin solution. For our purposes, only oxygen bound to $\mathrm{Hb}$ can be carried by blood. There is small amount that is dissolved in the plasma of the blood, however, this amount is physiologically insignificant and we will ignore it. This means that the maximum amount of oxygen that can be carried by blood is determined by the amount of $\mathrm{Hb}$. When every oxygen binding site on all the $\mathrm{Hb}$ molecules are occupied by oxygen, the blood is said to be $100 \%$ saturated and the blood cannot carry any more oxygen. When half of the sites are filled with oxygen, the blood is said to be 50\% saturated (I expect that you have the picture). The following graph demonstrates the effect that $\mathrm{pO}_{2}$ has on the percent saturation of $\mathrm{Hb}$. This curve was created by a scientist who exposed $\mathrm{Hb}$ to different $\mathrm{PO}_{2}$ then determining the \% saturation of $\mathrm{Hb}$ at each $\mathrm{pO}_{2}$. To determine the \% saturation of $\mathrm{Hb}$ at a given $\mathrm{pO}_{2}$, find the $\mathrm{pO}_{2}$ on $\mathrm{X}$-axis and draw an imaginary line up until you reach the red curve. Then read the \% saturation on the Y-axis. This has been done for you at two important points, a $\mathrm{pO}_{2}$ of $40 \mathrm{~mm} \mathrm{Hg}$ (the $\mathrm{pO}_{2}$ that is normally at the capillaries in resting tissues) and a $\mathrm{pO}_{2}$ of $100 \mathrm{~mm} \mathrm{Hg}$ (the $\mathrm{pO}_{2}$ that is normally in the capillaries in the lungs - this is constant and does not change Hemoglobin and Oxygen Binding under normal circumstances). Under normal circumstances, these are the only values that we must consider in a normal resting individual.Find the arrow that originates from $100 \mathrm{~mm} \mathrm{Hg}$ you should be able to discover that the $\mathrm{Hb}$ will be about $97 \%$ saturated (which means that $97 \%$ of all oxygen binding sites will be occupied with oxygen) - just about $100 \%$. Since the $\mathrm{pO}_{2}$ of the capillaries in the lungs is $100 \mathrm{~mm} \mathrm{Hg}$ (actually, it is a bit higher), then the $\mathrm{Hb}$ in these capillaries will be almost completely saturated with oxygen. Since the $\mathrm{pO}_{2}$ of blood cannot change until the blood reaches the capillaries in the tissues, all arterial blood will be just about $100 \%$ saturated and cannot not carry any more oxygen.

Now, find the arrow that originates from $40 \mathrm{~mm} \mathrm{Hg}$. At this partial pressure, the $\mathrm{Hb}$ is less saturated about $70 \%$. This is the typical $\mathrm{pO}_{2}$ in the capillaries of resting tissues. This means that the $\mathrm{Hb}$ in these capillaries are only $70 \%$ saturated. Since the blood entering these capillaries was 100\% saturated (this blood is coming from the lungs) but is only $70 \%$ saturated when leaving the tissues. What happened to the other $30 \%$ ? This oxygen was released from the $\mathrm{Hb}$ and is delivered to the tissues. Now, imagine that the tissue is more active so that it is using more oxygen. This will mean that there is less oxygen (a lower partial pressure) in this tissue. Let us imagine that due to the increase use of oxygen by the tissue, the $\mathrm{pO}_{2}$ of the tissues is $30 \mathrm{~mm} \mathrm{Hg}$ instead of the normal $40 \mathrm{~mm} \mathrm{Hg}$. If you check the graph, you will find that the $\% \mathrm{Hb}$ saturation at this $\mathrm{pO}_{2}$ is about $61 \%$. Since the blood entering these capillaries was 100\% saturated (it is coming from the lungs) and is $61 \%$ saturated when leaving the tissues, the rest (39\%) was released and delivered to the tissues. This is more oxygen then was delivered during normal conditions in which the $\mathrm{pO}_{2}$ is $40 \mathrm{~mm} \mathrm{Hg}$ (remember the blood leaving the tissues in this case was about $70 \%$, see above) which is what one would want to occur. If the tissue was so actve that the $\mathrm{pO}_{2}$ is ony $20 \mathrm{~mm} \mathrm{Hg}$, even more oxygen will be released - convince yourself that this is true by using the graph. The bottom line is that $\mathrm{Hb}$ is made so that it will automatically deliver more oxygen to those tissues that are using more oxygen go to the Bohr Effect. The function of oxygen transport and storage in higher animal is provided by Haemoglobin and Myoglobin. The former transport oxygen from it source (Lungs, gills, skin) to the site of its use in the mussels' cells. There is oxygen transport to myoglobin for its use in oxidation purpose. 
Before discussing the structure of this molecule the physiology of blood is briefly reviewed.

1. Myoglobin must have the greater affinity for binding $\mathrm{O}_{2}$ than haemoglobin in order to affect the transfer of $\mathrm{O}_{2}$ to the cells.

2. The equilibrium constant for myoglobin oxygen complexation is given by simple equilibrium expression.

$$
\begin{aligned}
& \mathrm{Mb}+\mathrm{O}_{2} \rightleftharpoons \\
& \mathrm{KM}_{\mathrm{M}}=\frac{\left[\mathrm{MbO}_{2}\right]}{[\mathrm{Mb}]\left[\mathrm{O}_{2}\right]}
\end{aligned}
$$$$
\mathrm{MbO}_{2}
$$

If ' $\mathrm{f}$ ' is represent the function of myoglobin molecule bearing $\mathrm{O}_{2}$ and ' $\mathrm{p}$ ' represents the equilibrium partial pressure of oxygen then the equation (1) becomes.

$$
\begin{aligned}
& K_{M}=\frac{f}{(1-f) p} \cdots \cdots \\
& f=K_{M}(1-f) p \\
& f=K_{M} p-K_{M} f p \\
& K_{M} p=f+K_{M} f p \\
& K_{M} p=f\left(1+K_{M} p\right) \\
& f=\frac{K_{M} p}{1+K_{M} p}
\end{aligned}
$$

This is equation for hyperbolic curve shown in following Fig.6

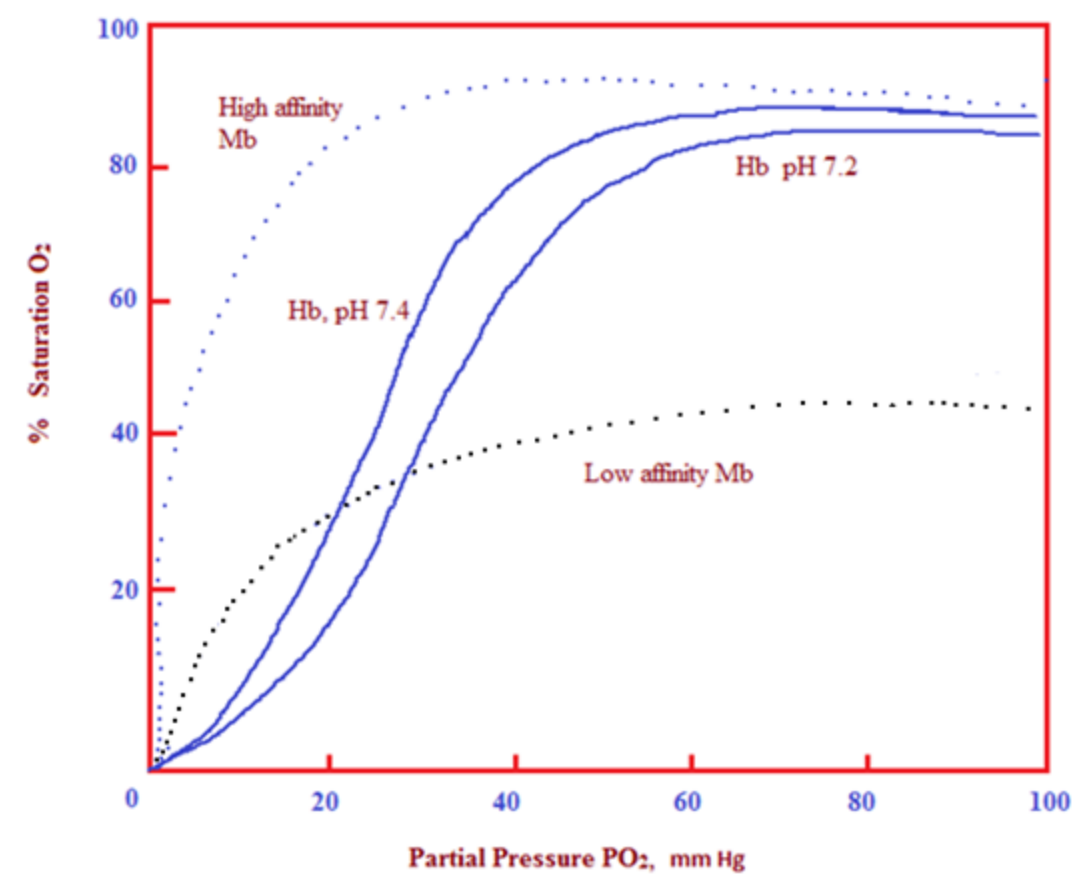

Fig. 6. Physiological benefit of cooperativity and hetrotropic allosteric effectors ${ }^{[31]}$ 
The myoglobin curve in Fig.6. Correspond to equation (2) but the haemoglobin curve does not follow such an equation. Therefore the above equation (Equ.2) modified by $\mathrm{pO}_{2}{ }^{\mathrm{n}}$ in place of $\mathrm{pO}_{2}$. Where $\mathrm{n}=2.8$. Myoglobin is largely converted to oxymyglobin even at low $\mathrm{O}_{2}$ concentration as obtained in the cells.

3. The equilibrium constant for formation of oxyhaemoglobin is somewhat more complicated. The expression is written as.

$$
\begin{aligned}
& \mathrm{Hb}+\mathrm{O}_{2} \rightleftharpoons \mathrm{HbO}_{2} \\
& \mathrm{~K}_{\mathrm{H}}=\frac{\left[\mathrm{HbO}_{2}\right]}{[\mathrm{Hb}]\left[\mathrm{O}_{2}\right]^{2.8}} \\
& \mathrm{f}=\frac{\mathrm{K}_{\mathrm{H}} \mathrm{P}^{\mathrm{n}}}{1+\mathrm{K}_{\mathrm{H}} \mathrm{P}^{\mathrm{n}}}
\end{aligned}
$$

Where $\mathrm{n}=2.8, \quad \mathrm{f}=$ partial saturation of oxygen with Myoglobin and Haemoglobin

The exact value of ' $\mathrm{n}$ ' depends on $\mathrm{P}^{\mathrm{H}}$. The 2.8 exponent for $\mathrm{O}_{2}$ result from the fact that a single Haemoglobin molecule can accept $4 \mathrm{O}_{2}$ molecule and the binding of four sites is not independent. If they acted independtly they give us curve identical to that of Myoglobin. It is called co - operativity of 4 haem group that produces the curve shown in Fig.6. If only one oxygen is present perhaemoglobin molecule, it dissociates more readily then from a mole oxygenated species. The net result is that at low oxygen concentration haemoglobin is less oxygenated and at high $\mathrm{O}_{2}$ concentration it is more oxygenated as shown in Fig.6. This phenomenon is called the $\mathrm{CO}$ - operativity and $\mathrm{pH}$ dependent effect is called Bohar effect. High spin Fe (II) porphyrin complexes, including the active site in $\mathrm{Hb}$ and $\mathrm{Mb}$, involve puckering and twisting of the porphyrine macrocycle, whereas a low spin Fe (II) ion has a smaller diameter can fit comfortably in to the ring. When $\mathrm{O}_{2}$ coordinates to $\mathrm{Fe}^{2+}$, the complex changes into low spin state $\left(\mathrm{t}_{2 \mathrm{~g}}{ }^{6} \mathrm{e}_{\mathrm{g}}{ }^{0}\right)$ the $\mathrm{Fe}$ (II) ion shrink a little and moves into the plane. This structure change can be verified by X-Ray diffraction. These types of five coordinate heam complex of Fe (II) are always high spin. The diameter of high spin $\mathrm{t}_{2 \mathrm{~g}}{ }^{4} \mathrm{eg}_{\mathrm{g}}{ }^{2} \mathrm{Fe}$ (II) ion is larger than that of central hole $(\sim 200 \mathrm{~nm})$ in the porphyrin ring. High spin Fe (II) porphyrin complexes including the active site in $\mathrm{Hb}$ and $\mathrm{Mb}$ involve puckering and twisting of the porphyrin macrocycle, whereas a low spin $\mathrm{Fe}$ (II) ion has a smaller diameter can fit comfortably in to the ring. When $\mathrm{O}_{2}$ coordinate to $\mathrm{Fe}^{2+}$ the complex changes into low spin state $\left(\mathrm{t}_{2} \mathrm{~g}^{6} \mathrm{e}_{\mathrm{g}}{ }^{0}\right)$ The $\mathrm{Fe}$ (II) ion shrink a little and moves into the plane. Haemoglobine is less efficient at $\mathrm{O}_{2}$ uptake under low $\mathrm{O}_{2}$ Pressure whereas myoglobin is very efficient. For example in muscle tissue where $\mathrm{pO}_{2}$ is small. There is a thermodynamically favorable $\mathrm{O}_{2}$ transfer from $\mathrm{HbO}_{2}$ to $\mathrm{MbO}_{2}$ in order to pass $\mathrm{O}_{2}$ into the cell. The oxygen free $\mathrm{Mb}$ is a five coordinate high spin Fe (II) complex with four of the coordination position occupied by four of the porphyrin ring $\mathrm{N}$ atoms and at fifth by the $\mathrm{N}$ atom of an imidazole ligand of a histidine residue. In the biological system the stability of $\mathrm{Fe}^{2+}$ in myoglobin and haemoglobin is a result of the globin protein of the molecule, protein chain folded around the haem. The globin part produced hydrophobic environment around haem and coiled shape. 


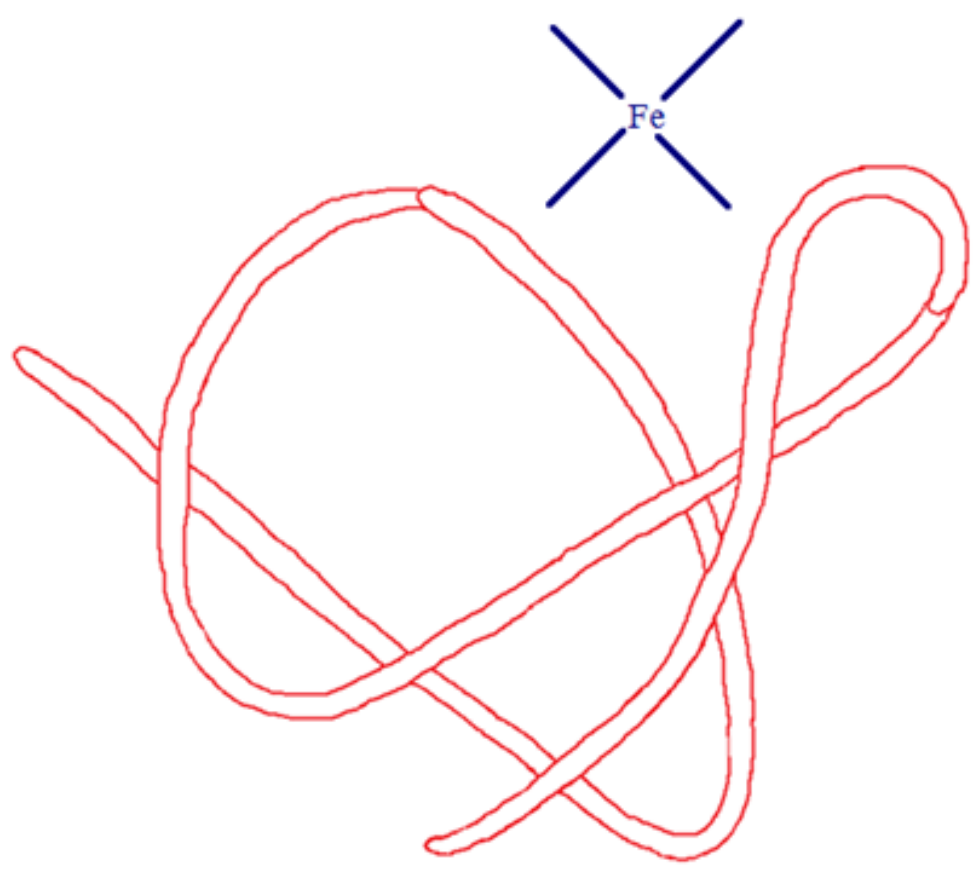

Fig. 7. Folded chain of Myoglobin

\section{Conclusion}

Iron is an essential trace element that is used to form molecules in the body, such as hemoglobin. Ferritin is the protein within the body that stores iron and releases it through channels in a controlled fashion. The unique structure of ferritin forms a spherical shell in which the iron is "stored" as Fe(III) in a crystalline mineral. Ferritin consists of 24 peptide subunits that form two types of channels where these subunits intersect; the 3-fold channel is polar and the 4-fold channel is nonpolar. (The residues that line the channels determine the polarity of the channel.) When the $\mathrm{Fe}(\mathrm{III})$ in the crystalline mineral is reduced to $\mathrm{Fe}(\mathrm{II})$, the iron becomes solvated and ferritin releases the solvated iron, $\left[\mathrm{Fe}\left(\mathrm{H}_{2} \mathrm{O}\right)_{6}\right]^{2+}$, through the 3-fold polar channel. Hence, ferritin can control the amount of available iron in the body, preventing iron disorders like anemia and iron overload. The three-dimensional structure of ferritin is crucial to its function within the body. (In fact, the threedimensional structure of any molecule is critical in determining a molecule's properties and function.) Hence, to better understand ferritin's role in the body, we used different types of molecular representations to study ferritin's three-dimensional stucture. Each representation used in this tutorial gives important information about ferritin. However, none of the representations by themselves can tell us everything we need to know about ferritin. Only by recognizing the value and limitations of each type of representation, and using these representations in conjunction with one another and with other information about the molecule, can we begin to understand the complex relationship between the protein's structure and its function.

\section{References}

[1]. T.H. Bothwell, Iron metabolism in man. London, Blackwell Scientific Publications. (1979).

[2]. L. Hallberg, Iron absorption and iron deficiency. Hum Nutr:Clin. Nutr., (1982). 36:259-278.

[3]. P.R. Dallman, Biochemical basis for the manifestations of iron deficiency. Ann. Rev. Nutr., 6. (1986)13-40.

[4]. J.H., Brock, J.W., Halliday, \& L.W. Powell, Iron metabolism in health and disease, London, W.B. Saunders Company Ltd. (1994).

[5]. L.C. Kühn, Control of cellular iron transport and storage at the molecular level. In: Hallberg LA, et al., eds. Iron nutrition in health and disease. p. 17-29. London, John Libbey \& Company.(1996).

[6]. D.P., Mascotti, D.Rup, \& R.E. Thach, Regulation of iron metabolism: Translational effects Medicated by iron, heme and cytokines. Ann. Rev. Nutr. 15 (1995)239-61.

[7]. I. Bertini, H. B. Gray, S.J. Lippard and J. S. Valentine, Bioinorganic Chemistry, (1994)167-252.

[8]. Morrison and Boyd, Organic Chemistry, (Allyn and Bacon, 1983).

[9]. L. Stryer, Biochemistry, (W.H. Freeman and Co, San Francisco, 1975).

[10]. Streitweiser and Heathcock, Introduction to Organic Chemistry, (MacMillan, New York, 1981).

[11]. C. H. Barlow et at. Biochem. Biophys. Res. Comm. 55 (1973), 91-95.

[12]. L. Pauling, Stanford Med.Bull.6 (1948), 215-222.

[13]. L. Pauling, Nature 203 (1964), 182-183.

[14]. J. J.Weiss, Nature 202 (1964),83-84.

[15]. J. S. Griffith, Proc. Soc. a 235 (1956), 23-36.

[16]. H. B. Gray, Adv. Chem. Ser. 100 (1971), 365-389. 
[17]. L. Pauling and C. D. Coryell, Proc. Natl. Acad. Sci.USA 22 (1936), 210-216.

[18]. J. P. Savicki, G. Lang, and M. Ikeda-Saito, Proc. Natl. Acad. Sci. USA 81 (1984), 5417-5419

[19]. T. G. Spiro, in A. B. P. Lever and H. B. Gray, eds. Iron Porphyrins, Addison-Wesley (1983), Part II,84-159.

[20]. B. B. Wayland, J. V. Minkiewicz, and M. E. Abd-Elmageed, J.Am.Chem.Soc.96 (1974), 2795-2801.

[21]. B. B. Wayland and L. Olson, J. Am. Chem. Soc. 96,(1974)637-641.

[22]. R. B. Frydman and B.Frydman, Acc. Chem. Res.20 (1987), 250-256

[23]. F. A. Cotton and G. Wilkinson, Advanced Inorganic Chemistry: A Comprehensive Text, Wiley, $4^{\text {th }}$ ed.1980.

[24]. J. L. Hoard, in K. M. Smith, ed., Porphyrins and Metalloporphyrins, Elsevier, 1975, 317-380

[25]. S. M. Peng and J.A.Ibers,J. Am.Chem.Soc.98 (1976),8032-8036

[26]. V. L. Goedken and S. M. Peng, J.Am.Chem.Soc.96 (1974), 7826-7827.

[27]. V. L.Goedken et al., J. Am. Chem. Soc. 98 (1976), 8391-8400.

[28]. a. D.H.Busch et al., Proc. Natl. Acad. Sci.USA 78 (1981, 5919-5923.

[29]. b. K. Kim et al., J. Am. Chem. Soc. 111(1988), 403-405

[30]. c. X.Y. Li and T. G. Spiro, J. Am. Chem. Soc. 110(1988), 6024-6033.

[31]. d. K. Kim and J. A. Ibers, J. Am.Chem.Soc.113 (1991), 6077-6081.

[32]. J. Kurian et al., J.Mol.Biol.192 (1986), 133-154.

[33]. A.Bionconi et al., Biochim. Biophys. Acta 831 (1985), 114-119

[34]. K. Imai, Allosteric Effect in Haemoglobin, Cambridge University Press, (1982) 